\title{
Preparing a Negotiated R\&D Portfolio with a Prediction Market
}

\author{
Cédric Gaspoz, Yves Pigneur \\ Faculty of Business and Economics (HEC), University of Lausanne, Switzerland \\ \{cedric.gaspoz,yves.pigneur\}@unil.ch
}

\begin{abstract}
The main objective of this research is to use prediction markets as negotiation agents, for supporting $R \& D$ portfolio management. To support this research, we iteratively designed, developed, operated and evaluated several prototypes. We start by presenting the weaknesses of the current techniques for managing $R \& D$ portfolio. Then, we intend to demonstrate that prediction markets correct these weaknesses in $R \& D$ portfolio management. Furthermore, following a design science paradigm, we illustrate the design of our artifacts using build-andevaluate loops supported with a field study, which consisted in operating the prediction markets in different settings.
\end{abstract}

\section{Introduction}

R\&D portfolio management is a critical task for the majority of the large companies. Several studies evaluated the practices in "Fortune 500" companies, finding that there is neither a single method nor a solution applicable to all companies $[8,20]$. The most recent investigations [7,9] showed that to be effective, portfolio management must apply a mix of various qualitative and quantitative methods. The use of quantitative methods presents weaknesses, mainly for (1) selecting the right criteria, (2) collecting the data, (3) and negotiating the portfolio between the different stakeholders.

Whereas many stakeholders, such as the different business units, are involved in the portfolio decision process, a "negotiation support systems" could be the appropriate solution to speed up the process. However, it will not significantly reduce the communication effort. We suggest a paradigm shift with a new tool to address the portfolio selection.

The research assumption is that a prediction market could improve R\&D portfolio management. Prediction markets are future markets evaluating the projects potential of a portfolio. Prediction markets collect information from different actors, who trade on the market, and aggregate this information in an automatically negotiated equilibrium price, corresponding to the valuation of the project. Such market mechanism addresses the three weaknesses mentioned above: (1) no more criteria to be explicitly selected, (2) less data to be collected, and (3) fewer issues to be explicitly negotiated between actors. These three activities are replaced by the buy and sell trading of claims concerning portfolio contents.

For this research, we adopted a design science method, with its build-and-evaluate loop. We designed and implemented different versions of prediction markets, which we operated and evaluated on small and large-scale experiments.

The next section presents the R\&D portfolio management and its weaknesses. Section 3 gives the prediction market foundations, its automatic negotiation kernel, and the advantages in a $R \& D$ context. Section 4 defines the artifact we designed and describes the main design issues. Section 5 presents the evaluation phase; we suggest 5 lessons based on the experiments we managed for operating and validating prediction markets.

\section{R\&D Portfolio Management}

$\mathrm{R} \& \mathrm{D}$ project portfolio selection is a periodic activity, which aims at optimizing the research effort of the company. It enables the company to select a portfolio which corresponds to its strategic objectives, without exceeding the resources available. The selection of a powerful project portfolio is a delicate exercise. On one hand, it requires wide competencies of strategic management and the associated tools regarding the objective criteria. On the other hand, it necessitates very good competencies in negotiation regarding the subjective criteria as well as the final choice of the portfolio composition.

"The portfolio decision process is characterized by uncertain and changing information, dynamic 
opportunities, multiple goals and strategic considerations, interdependence among projects, and multiple decision makers and locations" [9].

Chien [7] provided an extensive literature review on portfolio selection and showed the inherent limitations in the existing $\mathrm{R} \& \mathrm{D}$ project selection models as follows: (1) inadequate treatment of multiple, often interrelated, evaluation criteria; (2) inadequate treatment of interrelationships among projects; (3) inability to handle non-monetary aspects; e.g. diversity among projects; (4) no explicit recognition and incorporation of the experience and knowledge of the R\&D managers (i.e. the decision makers) and (5) perceptions by $\mathrm{R} \& \mathrm{D}$ managers that the models are difficult to understand and use.

Cooper [9] showed that the combination of individually good projects unnecessarily constitutes the optimal portfolio for the firm. This is often the case with firms having too many trivial projects and not many projects to yield major competitive advantage. Many authors proposed different frameworks for selecting $R \& D$ projects portfolio $[1,7,9,27]$.

The invariants of these different frameworks are: (1) maximizing the value of the portfolio, (2) achieving a balanced portfolio and (3) building strategy into the portfolio.

Whereas the two last stages are relatively well documented and supported by different frameworks using very widespread visualization techniques like bubble diagrams and scoring models, the first stage is the subject of a plethora of different methods which require large investments in time and resources for the data collection.

Liyanage refers to more than 200 quantitative and qualitative methods for selecting R\&D projects in his study [21]. The most often used methods are: the Net Present Value, the Expected Commercial Value, the Productivity Index, the Options Pricing Theory and the Dynamic Rank-Ordered List. All these methods rely on various data which must be collected/evaluated or estimated before being used in the models. The principal issue concerning these data is their inaccuracy or unreliability, making the financial methods yielding the worst portfolio results [9]. This is not related to the fact that these models lack rigor; rather, it results from very poor data and forecasting in new product projects.

We raised three main issues: (1) selecting the right criteria, (2) collecting the data and (3) negotiating the evaluation. These issues are presented in the following sections. In Section 3, we will then show how prediction markets can solve these issues.

\subsection{Selecting the right criteria}

To be able to compare different projects at different stage with different goals, the senior managers first have to select the right criteria, applicable to all projects. These criteria may be financial like NPV or ECV, commercial like market shares, based on the consumed or planned resources, related to the pricing or the probability of technical success. To select the right set of criteria, the company uses the experience of its senior managers as well as some intern guidelines, principally financial and used in the budgeting process. This set of criteria can be elaborated iteratively by the experts with Delphi-like or NSS methods. The output of this process is very important because it will influence the selection process of the portfolio.

\subsection{Collecting the data}

Once the criteria determined, it is necessary to collect the quantitative information necessary to their evaluation. During the initial stage of the project, the lack of concrete information leads the various experts to make projections, estimates or extrapolations to quantify the various indicators. More reliable data will only be available later, according to the project advance. Consequently, their use in a sophisticated mathematical model has only little significance in phase of launching and could lead to very inaccurate results. However, this initial phase is of great importance for the decision to incorporate or not the new project in the global portfolio.

Another problem concerning the data collection is the constant update of these data during the whole project life. Even if the data tend to approach reality according to the project advance, their acquisition remains tiresome. Whereas certain data can be easily extracted from the company's reporting tools, some require a lot of work. Thus, for example, the data concerning new technologies acceptance, future market shares, product lifespan, competitors' actions as well as others must be the subject of a new study for each portfolio actualization. This makes the process inflexible and often leads managers to use obsolete data, having no time and resources to gather up-to-date information.

\subsection{Negotiating the evaluation}

Since the R\&D portfolio management is often a team activity and implies several stakeholders (i.e. business units), the decision issues and positions are often the result of a negotiation process. In line with the previous comment on criteria selection, $R \& D$ portfolio management could be considered as a multi- 
actor negotiation or multi-criteria decision-making process [5]. Several models have been proposed in the negotiation literature. Kersten [19] suggests a negotiation model with 5 phases: (1) search for arena and selection of communication mode (synchronous or not), (2) agenda setting (decision attributes), (3) exploring the field (best alternatives for negotiation agreement), (4) narrowing the difference and searching for the agreements (with compromises, offers and counter-offers, ...), and (5) agreement assessment and fulfillment. This kind of model and the associated Negotiation Support Systems (NSS) facilitate communication activities. However, they speed the process and eliminate ambiguities but they do not reduce the communication intensity. We claim that with a new paradigm we could drastically reduce the communication effort itself, substituting the multistakeholder negotiation process by a market mechanism.

To solve these recurring problems, we propose to use a technique, derived from financial theories, which is based on prediction markets. The prediction markets are future markets whose assets are tied to a particular project. The main characteristic of these markets is to be able to incorporate a wide range of information disseminated through a great number of actors having very different interests. Information is automatically aggregated into one negotiated equilibrium price, the discrete evaluation of the value of the project.

Although, to our knowledge, prediction markets were not yet used in this configuration, using a prediction market in complement of qualitative methods, must allow managers to obtain discrete data in a relatively economic and fast way. In addition, by their nature, prediction markets allow to obtain not only one discrete value at a given time, but also the evolution of this equilibrium during the whole project life, making this value much significant than a simple discrete value.

\section{Prediction markets foundations}

There are many definitions of prediction markets, idea futures (IF) markets, information markets, virtual stock markets (VSM), securities trading of concepts (STOC) markets. Hanson, one of the fathers of this concept recently wrote:

"Information markets can be used to elicit a collective estimate of the expected value or probability of a random variable, reflecting information dispersed across an entire population of traders. The market prediction is not usually an average or median of individual opinions, but is a complex summarization reflecting the game-theoretic interplay of traders as they obtain and leverage information, and as they react to the actions of others obtaining and leveraging their own information" [16].

Prediction markets have been used in many different public contexts and used as case studies in many scientific papers. The Iowa Electronic Market ${ }^{1}$ (IEM) is a well-known small-scale, on-line, realmoney, prediction market, run by the University of Iowa, in which contracts correspond to political or economic events. The Hollywood Stock Exchange ${ }^{2}$ is an e-market along the same lines as the IEM, which allows people to use virtual currency to speculate on movie-related questions. Other examples include TradeSports $^{3}$, a futures electronic market or gambling forum, initially for sports events, and now for a rich set of political futures, financial contracts, and entertainment. The Foresight Exchange ${ }^{4}$ is a playmoney prediction market to test the ability to predict the outcome of future events, check the odds of upcoming events, and make bets, among others for science and technology events. NewsFutures ${ }^{5}$ also trades political, finance, and technology (pharmaceutical) events, with virtual currency but real prizes. The Tech Buzz Game ${ }^{6}$ is a play-money market hosted by Yahoo! Research in collaboration with O'Reilly about the future of technology. It is also the first market using the dynamic pari-mutuel (DPM) automated market maker algorithm from Pennock [22]. A final example of public e-markets is the controversial and rapidly-aborted Policy Analysis Market, or FutureMap [13] sponsored by the US Department of Defense, which should have allowed speculating about strategic and geopolitical issues.

Prediction markets have also been used inside corporations. An internal market, Information Aggregation Mechanism or IAM, at Hewlett-Packard produced more accurate forecasts of printer's sales than the firm's internal specialists [23]. At Siemens, an internal market was tested for predicting the progress (due date) of a software project better than conventional planning tools. The MIT Securities Trading of Concepts or STOC has used the pricing mechanism for marketing research using pseudosecurities market to measure preferences relating to new products. Berg [4] shows how prediction markets can be used for decision support. Finally, Google launched an internal market to forecast product launch dates, new office openings, and many other items of strategic importance to Google.

\footnotetext{
${ }^{1}$ http://www.biz.uiowa.edu/iem/

2 http://www.hsx.com/

${ }^{3} \mathrm{http}: / /$ www.tradesports.com/

${ }^{4} \mathrm{http}: / /$ www.ideosphere.com/

${ }^{5}$ http://us.newsfutures.com/

${ }^{6} \mathrm{http}: / /$ buzz.research.yahoo.com/
} 
The first software platform and open source toolkits are appearing for building prediction markets. NewsFutures ${ }^{7}$ licenses its proprietary Prediction Trader platform ${ }^{8}$ to enable the rapid development, operation, and administration of prediction markets. Prediction Trader is used to power MIT Technology Review's Innovation Futures: a prediction exchange concerning emerging technologies and the business of technological innovation. Hibbert [18] proposes developing an open-source toolkit for creating prediction markets, called Zocalo ${ }^{9}$, in order to catalyze broader adoption of markets in academia, industry, and throughout society.

Many scientific papers studied the design of prediction markets as well as their principal issues. Spann [26] evaluates different design possibilities as well as the forecast accuracy and performance of prediction markets compared to expert prediction for their application to business forecasting. He shows that the markets bet the experts most of the time. Furthermore, he proposes a new validity test for prediction markets forecasts. Chen [6] proposes and experimentally verifies a market-based method to aggregate scattered information so as to produce reliable forecasts regarding uncertain events; he empirically demonstrates that nonlinear aggregation mechanisms vastly outperform both the imperfect market and the best informed traders. Wolfers [28] showed that the success of the prediction market in generating trade depends critically on attracting uninformed traders. To solve this issue, prediction markets can incorporate various trading and rewarding mechanisms. Servan-Schreiber [25] sets up a realworld on-line experiment showing that play-money markets with real prizes performed as well as real money markets. They speculate that real-money markets may better motivate information discovery while play-money markets may yield more efficient information aggregation. Whereas simplest prediction markets use a continuous double auction mechanism, most advanced implement a market maker in order to fluidize the transactions and to optimize the information aggregation mechanism. After introducing market scoring rules, Hanson [12] considers several design issues, including how to represent variables in order to support both conditional and unconditional estimates, how to avoid becoming a money pump via errors in calculating probabilities, and how to ensure that users can cover their bets, without needlessly preventing them from using previous bets as collateral for future bets. Finally, Rhode [24] studied a century of

\footnotetext{
${ }^{7} \mathrm{http}: / /$ www.newsfutures.com/

${ }^{8} \mathrm{http}: / /$ us.newsfutures.com/home/trader.html

${ }^{9} \mathrm{http} / / /$ zocalo.sourceforge.net/
}

manipulations of prediction markets. His work suggests that it is difficult and expensive to manipulate prediction markets beyond short periods of time. Studies on TradeSport point out that manipulations are reverted within minutes by other traders.

We will now show how prediction markets can solve the issues raised in Section 2 and be applied to $\mathrm{R} \& \mathrm{D}$ portfolio management.

\subsection{Selecting the right criteria}

Used for $R \& D$ portfolio management, prediction markets allow, once the project proposal been released, creating a new claim tied to the project and put on the market. As of this moment, all the actors directly or indirectly linked to the project, can trade (buy or sell) contracts concerning the project, based on their own appreciation of the project. The traders are the leaders and the teams of the project, but also the senior management, people from marketing, finance, as well as from all the other businesses units concerned by the $\mathrm{R} \& \mathrm{D}$. Their narrow expertise of a particular company activity, like research, but also marketing, sales, customer care or finance will enable them to form their own opinion about the project, under the particular lighting of their activity field. The result of all aggregated appreciations will de facto include a multitude of implicit criteria related to all company activities. It becomes thus easy to obtain a discrete evaluation of each project, allowing classifying them by order of importance or clusters.

Using implicit comparison criteria, prediction markets enable to reach a great diversity of appreciation criteria in a completely transparent way and to aggregate them in a price, representing the actual consensus on the claim. This is particularly true when an ontology, shared by all actors, is used to describe the projects claims, enabling each trader to have the same reference frame.

\subsection{Collecting the data}

In an $R \& D$ portfolio management context, prediction markets enable each actor, at any time, to integrate his private information by buying or selling contracts according to the difference between the equilibrium and its own confidence. In this manner, the equilibrium price, while undergoing constant adjustments, will gradually incorporate more and more information due to the aggregating mechanism of the market. The trader's goal being to maximize its personal performance on the market, he will try to make profit each time he is in possession of information enabling him to adjust his position. To motivate him to be reactive, the prediction market 
enables to rank the traders obtaining the best performances, performances which can be rewarded by the company in form of prizes or bonus.

Finally, the use of prediction markets for R\&D allows solving another problem concerning the portfolio maximization: the update of the data. Very often, the data cannot be regularly updated for the portfolio reviews and the senior management has to deal with the progress reports to base their analysis. With the prediction markets, the quote of the contract is fluctuating throughout the whole project life, after each transaction carried out by the traders. Thus, any modification of an internal or external factor related to the project will initiate a buy or sell order issued by the actor in possession of new information. This transaction will make evolve the price to a new equilibrium. In this manner, the senior managers can base their decision not only on the price of the contract at a given moment, but also on its evolution during a given period. This concept of continuity of the evaluation also allows a better comparison between projects. In addition to one discrete value, it allows a comparison of the trend of the price of each contract (i.e. projects in a growing or declining phase).

Using a relatively basic mechanism, based on the buy and the sell of contracts, prediction markets can aggregate very efficiently and in real time the information disseminated between a wide range of actors, making superfluous the implementation of a specific actualization process. In addition, this quote not only represents the actualized consensus concerning the value of the project, but also represents the evolution of this consensus during the whole project life.

\subsection{Negotiating the evaluation}

On an R\&D prediction market, the negotiations of each project relative value is the result of the various sell or buy orders placed by the traders. These orders are processed by a market maker in a completely automatic way, allowing to carry out the transaction and to establish the new equilibrium price. Thus instead of using an inter-actors negotiation support system, we use a transparent system allowing each actor, at any time, to negotiate a new equilibrium price with the market-maker.

In addition, like the stock exchange portfolios, the traders do not rely on unlimited resources. Their relative influence on the market evolves according to their performances. Thus, the best informed traders will benefit from the appreciation errors of the less informed ones or from those trying to manipulate the quotation to make profit and to increase their influence on the market. At the same time, relative to their losses on the market, the others traders will see their possibility of influencing the course reduced. For that reason and in spite of the significant actors' number, the equilibrium price is the result of a consensus between all the actors, according to their relative influence, not based on their position in the company, but on their overall performance.

Using an automatic market-maker, prediction markets enable obtaining a continuous negotiation of the value of each project of the portfolio among all the actors, according to their relative influence on the market. In addition, this mechanism allows obtaining a greater adhesion towards the decisions since the price at a given moment is the result of the negotiation of all actors concerning the advisability of carrying out a given project.

\section{Design issues}

To design our prediction market named MarMix we adopted the recommended build-and-evaluate loop from the design science framework [17]. An artifact is built and assessed with a field study before being refined and reassessed. In our case, these field studies started with a small number of actors and conclude by involving more than 200 actors. We conducted three iterations of this loop, which are briefly presented in the next chapter.

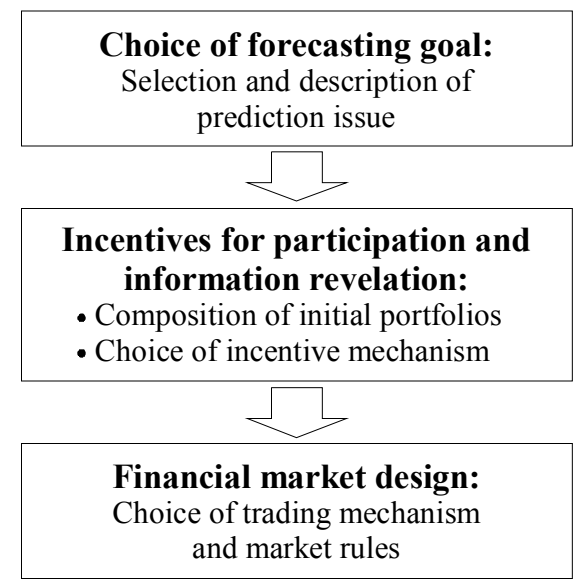

Figure 1. Steps for designing a virtual stock market from Spann and Skiera [26]

To support our design, we reviewed all the opensource prediction markets available at the time of our first experiment. We decided to improve the work of Peter McCluskey on USIFEX ${ }^{10}$. His prediction market had the advantage of having been developed with a robust object-oriented programming methodology. In

\footnotetext{
${ }^{10} \mathrm{http} / / /$ www.usifex.com/
} 
addition, USIFEX was also the most complete software, implementing the majority of our requirements.

The R\&D community we consider in this research is a Swiss NSF program in the field of mobile information and communication systems. In order to define the characteristics of our prototype, we carried out a series of interviews during summer 2005 with researchers involved in the project, and with the person in charge of the project.

Finally, we adopted the three Steps for Designing a Virtual Stock Market from Spann and Skiera [26] (Figure 1) to design our artifact, as presented in the following sections.

\subsection{Choice of forecasting goal}

Prediction markets are able to make different types of predictions: YES/NO e.g. "We will sell 12000 pieces of product X during April 2008", linear e.g. "How many pieces of product $\mathrm{X}$ will be sold during April 2008?" or discrete e.g. "Project X will finish: a) in advance, b) on time, c) late". We chose a basic model, namely the forecasting of the occurrence or nonoccurrence of a particular event, in our case, the success of a particular project at his planned end. The payoff function related to this model is a "Winner takes all" function, represented by Span et al. [26] by:

$$
\begin{aligned}
& d_{i, T}=\left\{\begin{array}{ll}
v & \text { if particular event occured, } \\
0 & \text { otherwise, }
\end{array} \quad(i \in I),\right. \\
& d_{i, T}=\text { cash dividend of the stock modeling the outcome of } \\
& \text { the } i \text { th event at time } T \text {, } \\
& I=\text { index set of events, } \\
& T=\text { point or period in time that is relevant for the } \\
& \text { determination of the outcome of the event, } \\
& v=\text { cash dividend value. }
\end{aligned}
$$

Claim description. To allow each trader to acquire the same contracts comprehension, whatever his activity is, we improved MarMix by the development of a specific ontology to describe the projects claims. The goal of this ontology is to standardize the description of the claims to allow traders coming from other domains to quickly understand the underlying concepts. Our ontology takes the concepts of the futures markets and adds the specific concepts of the description of R\&D projects. Currently, the focus of the presented ontology is on research projects rather than on development ones.

We decided to split the definition of the claims into two parts. The first relates to the elements described as structural, which define the claim's terms, and the second defines the claim's proposal.
The structural elements are defined in such a way that all traders are rapidly able to understand the main points of the contract properties. They consist of the description, the judgment, the price and the type of the claim.

Due to the diversity of the prediction markets and the related claims, it is difficult to propose a generic framework for defining claim's proposal. We tried to characterize claims based on the interviews carried out at the beginning of the project as well as on the active

\begin{tabular}{|c|c|}
\hline Symbol & SLF \\
\hline Name & Sensor-Network deployed by SLF \\
\hline Type & Boolean \\
\hline Project & $\begin{array}{l}\text { Real-time avalanche and landslide analysis } \\
\text { through sensor networks }\end{array}$ \\
\hline Settle date & 31.07 .2009 \\
\hline Price & Minimum price: 0 , maximum: 100 \\
\hline Payment & $\begin{array}{l}\text { Winner-Takes-All (if the contract is TRUE: } 1 \text {, } \\
\text { if not: } 0 \text { ) }\end{array}$ \\
\hline Field of research & Research on sensor-networks \\
\hline \multicolumn{2}{|c|}{$\begin{array}{l}\text { The fluid-dynamics models used so far in predicting } \\
\text { mass movements such as avalanches rely on speculative } \\
\text { equations and very little is known about the internal } \\
\text { structure of avalanches. Field measurements only } \\
\text { provide insight into shape characteristics (e.g., } \\
\text { avalanche speed). }\end{array}$} \\
\hline \multicolumn{2}{|c|}{$\begin{array}{l}\text { The sensor network measures the displacement/velocity } \\
\text { field inside a flowing bulk. Before the material is } \\
\text { released, the sensor nodes are spread onto the surface or } \\
\text { inside the material. After release, the information of } \\
\text { each node is monitored to determine the flow structure. } \\
\text { The main tasks are twofold: constructing a sensor } \\
\text { network and interpreting the data to build more } \\
\text { accurate fluid-dynamics models. }\end{array}$} \\
\hline \multicolumn{2}{|c|}{$\begin{array}{l}\text { Deployment of a sensor-network under real conditions } \\
\text { to predict the risks of avalanche }\end{array}$} \\
\hline \multicolumn{2}{|c|}{$\begin{array}{l}\text { The SLF deployed a network of } 100 \text { nodes in an alpine } \\
\text { area to predict the risks of avalanche. The results } \\
\text { obtained by the sensors, as well as the treatments using } \\
\text { fluid-dynamics models, allow us to obtain valid results } \\
\text { with an error margin of } 20 \% \text { during a season ( } 01.11 \text { to } \\
\text { the } 30.04) \text {. }\end{array}$} \\
\hline
\end{tabular}
claims on the other markets. We noticed five important concepts: the sphere of activity, the state of the art, the goal of the research, the expected results and the measure of success, illustrated by the SLF claim in Table 1.

Table 1. The SLF claim on MarMix

The state-of-the-art section gives a short presentation of the research history. In this category we 
describe the previous steps necessary to formulate the goal of the research, the related work and present some major publications in the field. Such information will enable each researcher to situate the claim in its field of research.

The goal of the research describes the expected outcome of the research after a given time. These are global, long-term and not precisely defined goals, as they represent research in progress.

The expected results are the concrete elements, in the mid-term, that will result from the research. They may be products, demonstrations, patents, algorithms, creation of start-ups, standards or RFC.

The measure of success must precisely express the methods of evaluation of the awaited results. This evaluation should be objective and factual. We could, for example, specify the product's market share, the acceptance of a demonstration by the scientific community, the use of a patent and the publication of the results by the press.

IPO. We chose to treat the claims management in a different way from other prediction markets, which use a top-down process. Indeed, to guarantee the transmission of information between the researchers and the market, each trader was allowed to trade on the available claims. He was also allowed to propose new claims in connection with his field of research to test his research proposal before submitting an official project to his hierarchy. This led us to define a process of an IPO in four stages: (1) claim proposal, (2) discussion on the formulation of the claim, (3) price determination, by putting limit orders on the claim and finally (4) opening of the trade on the market.

\subsection{Incentives}

Based on the fact that there are no significant differences between real-money and play-money markets, as shown by Servan-Schreiber [25], we designed the market as a play-money market with tournaments based on individual performance level. Moreover, we included a play-money reward for traders who created new claims on the market, based on the quantity of contracts sold during the claim's life. Our choice of a play-money market was driven by the suggestion that researchers involved in the project are more likely to trade with play-money than with their own money. This configuration also allows us to attract less informed players, who do not take any personal risk, but improve the liquidity of the market [28]. Finally, this setup of the market has the advantage of enabling us to omit the legal considerations related to a real-money market, as stated in $[2,3,10]$.
To ensure that the study was relevant, we started the market during a workshop in the presence of hundred researchers. We proceeded with a workshop in the presence of computer scientists and telecom engineers without any financial background, followed by a longterm experiment.

After a first series of interviews, we noticed that interest is quite present within the community for this type of technology but the teams are centered on specific problems. Furthermore, it is difficult to get them interested in questions outside their field of work. Thus, we assume that the organization of workshops bringing together the participants by field of interest will create a certain dynamic on the platform, even if the traders limit themselves to a small proportion of the available claims.

We also tried to communicate the information to the traders via different channels such as email and information displays in the buildings. The latter played an important role in motivating the traders, and in some cases was more important than the prize itself.

Interfaces. Our goal was to develop a very intuitive interface in terms of usability, hiding the excessive financial aspects of the marketplace, to reduce the learning curve.

In order to play on the market, the trader needs enough private information to optimize his return on investment but also needs enough information from the market to take the right investment decision. For this purpose, we implemented various decision support information like graphics with daily, weekly, monthly and complete quote histories, historics of the daily quotes with trends and summaries, various top ten lists such as the biggest movements, gains, losses, the most active traders, claims. We also extended the real-time quotes with short- and long-term trends for each claim.

We also implemented a "1-Click trading" option to allow traders to pass market orders by directly clicking on a quote or to pass limit orders by clicking on the reverse transaction on order books. This option will be enhanced in the next release to allow traders to enter their own confidence related to a particular claim and pass the corresponding order on the market.

Finally, we added the possibility of trading via cellular phones, based on short text messages (SMS). In addition to the advantages in terms of portability, this development allowed us to simplify the interactions between the traders and the platform. We developed a syntax to reduce the instructions to the minimum, and to ensure that the exchanged messages conform to the SMS format. For example, the user send, "MARMIX BUY 25 SENSOR" to pass an order of 25 contracts of the claim sensor at the market price on the MarMix prediction market. 


\subsection{Market design}

To avoid falling into the problems of small markets (lack of movements and liquidity), we chose a continuous double auction mechanism with a market maker. On a prediction market, the market maker should be considered as an automatic negotiation agent, processing all buy and sell orders of the traders. This choice ensures that the traders can express their forecasts at any time, whatever the positions of the other traders. For the first prototype we selected logarithmic market-maker mechanism.

We rapidly realized that the chosen automated market maker algorithm, inspired by Hanson [14], was not designed to support large-scale experiments. The market price overreacts if many small orders and, in particular, short orders are put in, allowing traders to make disproportionate profits. Although this algorithm worked well on a small market, the number of concurrent orders placed at the same time on this large market showed the limits of our choice. Moreover, this function did not take into account the open orders in the book to establish the market price.

After reviewing the literature, we chose the design proposition of Hanson based both on a combinatorial market maker algorithm and on a book of orders [11]. This proposition is based on two other publications by Hanson, the Logarithmic Market Scoring Rules [15] and the Combinatorial Information Market Design [12]. We were also inspired by the work of Chris Hibbert on Zocalo for the implementation of these algorithms.

\section{Evaluation of the Experiments}

To test our design choices, we ran three experiments as stated in Section 4. We chose to iteratively test the interfaces and incentives, the market mechanism as well as the market-maker algorithm and finally the claim description and the incentives again in three separate experiments. This allowed us to focus the experiments on specific design issues. For this reason, we used non R\&D claims for the first two iterations, allowing us to carry out the experiments with students and staff from the university whereas the third iteration was carried out with the project R\&D program and researchers.

This first experiment gave us the opportunity to test the various mechanisms of prediction markets and to implement the design choices elaborated during the design phase. We experimented with a simple prediction market with few actors since Chen [6] illustrated that small markets are able to make accurate predictions.
To evaluate our design, we operated the prediction market and conducted several exploratory interviews with the actors of the experiment at the end of October 2005. We used the prediction market for a "one hour" laboratory experiment with 15 researchers trading five contracts, followed by a two-week experiment during which about thirty traders were able to trade the same five contracts.

The considerable difference in the number of participants between the two experiments showed us that the basic mechanisms of futures markets are not known by the researchers and that consequently, without direct supervision and an incentive mechanism, researchers are not motivated to trade on such a market.

Table 2. Key numbers resulting from the first experiment

\begin{tabular}{|l|r|}
\hline Number of traders & 28 \\
\hline Number of active traders $(>3$ orders $)$ & 11 \\
\hline Average orders by trader & 26 \\
\hline Number of claims & 5 \\
\hline Number of orders & 286 \\
\hline Number of contracts & 5093 \\
\hline
\end{tabular}

After our first small-scale experiment, we decided to run a second large-scale experiment to test the prototype. This second experiment took place with 99 traders, playing during six weeks on 16 claims in summer 2006. During the whole experiment, we had a total of 3'071 transactions, representing 144'248 contracts.

At the same time, we ran another experiment with the same prototype, dedicated to the prediction of the organizing city of the 2014 Winter Olympic Games, with 50 traders coming from various sport federations and specialized media.

Table 3. Key numbers resulting from the second experiment

\begin{tabular}{|l|r|}
\hline Number of traders & 114 \\
\hline Number of active traders $(>3$ orders $)$ & 99 \\
\hline Average orders by trader & 31 \\
\hline Number of claims & 16 \\
\hline Number of orders & $3 ' 071$ \\
\hline Number of contracts & $144^{\prime} 248$ \\
\hline
\end{tabular}

Finally, we started our third experiment (still in progress) with the project researchers and claims about mobile information and communication systems. The claims used at the beginning of this iteration are shown in Table 4. 
Table 4. Claims' list at the beginning of the third iteration

\begin{tabular}{|l|l|}
\hline CAR & $\begin{array}{l}\text { Large scale (10 vehicles) vehicular } \\
\text { network test }\end{array}$ \\
\hline AVALANCHE & $\begin{array}{l}\text { Sensor-networks deployed by the Swiss } \\
\text { Federal Institute for Snow and Avalanche } \\
\text { to detect the risks of avalanche in alpine } \\
\text { regions }\end{array}$ \\
\hline RFID & Mobile Phones with RFID in Switzerland \\
\hline ROBOTS & $\begin{array}{l}\text { Robots detect a ringing phone among a } \\
\text { hundred faster than humans }\end{array}$ \\
\hline MPAYMENT & $\begin{array}{l}\text { At the meeting of 2009, the majority of } \\
\text { the part-icipants will pay their train ticket } \\
\text { by mobile phone }\end{array}$ \\
\hline BUILDING & $\begin{array}{l}\text { Users helped by ludic interfaces are } \\
\text { better than intelligent buildings in energy } \\
\text { saving }\end{array}$ \\
\hline
\end{tabular}

Our experiments supported with our artifact led us to formulate five propositions to design a predictions market for $\mathrm{R} \& \mathrm{D}$ portfolio management.

Proposition 1: A prediction market for R\&D should integrate a standard framework to support claim formulation.

Using an indicator incorporated in the form of a price makes the evaluations comprehensible by all actors. Consequently, it is advisable to make sure that independently of their activity the traders have the same claims comprehension. Moreover, a structured framework helps defining claims or structuring interviews with concerned peoples.

Proposition 2: A prediction market for R\&D should integrate an easy IPO mechanism to support the innovation process.

The prediction market should allow researchers to test their research ideas among all actors, without needing a review process or preliminary validation. This direct access to the market removes internal barriers to innovation without requiring modifying usual selection processes.

Proposition 3: A prediction market for $R \& D$ should occult the financial mechanisms to reduce the trader's learning curve and increase his incentive

Observations resulting from our interviews showed that the researchers are by no means familiar with the underlying concepts such as limit orders necessary to play on a prediction market, which results in errors and discourages them from playing on the market. This implies specific usability requirements on the humancomputer interface.

Proposition 4: A prediction market for R\&D should allow the combination of group sessions with individual sessions to increase the incentive of the traders.

Group sessions allow obtaining very quickly an evaluation of the portfolio, generating a specific dynamic. Siemens used this configuration during one hour meetings, but it could also be used in a distance synchronous trading way (e.g. by opening the market for one hour every month).

Proposition 5: A prediction market for R\&D should integrate an automatic negotiation agent (i.e. market maker to increase the quality of the evaluation).

The market maker makes the market more reactive and fluid, allowing the traders to buy or sell each time new information is available. Thus the evaluation will aggregate more information, compared to a double auction market were the traders must wait for a similar offer to make the deal.

\section{Conclusion}

In this research, we designed and experimented a prediction market in an R\&D context. We confirmed the hypothesis that prediction markets seem to be suitable for supporting negotiated R\&D portfolio management.

We first exposed the current situation of $R \& D$ portfolio management in order to heighten awareness of the problem. We then provide a short description of the research carried out in prediction markets and what techniques have been used so far to study the phenomena of interest. We also expose the different theoretical foundations used in current prediction market research and justify our methodology choice. Our research contribution takes the form of five propositions to design a predictions market for R \& D portfolio management. These propositions mainly concern: (1) a framework and a process for defining parts of an R\&D portfolio, (2) a human-computer interface and a groupware setting with high usability requirement, (3) an automatic negotiation market maker.

\section{References}

[1] N. P. Archer and F. Ghasemzadeh, "An integrated framework for project portfolio selection," International Journal of Project Management, vol. 17, pp. 207-216, 1999.

[2] T. W. Bell, "Gambling for the Good, Trading for the Future: The Legality of Markets in Science Claims," Chapman Law Review, vol. 5, pp. 159-180, 2002.

[3] T. W. Bell, "Prediction Markets for Promoting the Progress of Science and the Useful Arts," George Mason Law Review, vol. 14, pp. 37-92, 2006. 
[4] J. E. Berg and T. A. Rietz, "Prediction Markets as Decision Support Systems," Information Systems Frontiers, vol. 5, pp. 79-93, 2003.

[5] T. X. Bui and M. Jarke, "Co-oP: A Group Decision Support System for Cooperative Multiple Critería Group Decision Making," Lecture notes in computer science, vol. 290, 1987.

[6] K.-Y. Chen, L. R. Fine, and B. A. Huberman, "Predicting the Future," Information Systems Frontiers, vol. 5, pp. 47-61, 2003.

[7] C. F. Chien, "A portfolio-evaluation framework for selecting $\mathrm{R} \& \mathrm{D}$ projects," $R$ and D Management, vol. 32, pp. 359-368, 2002.

[8] R. G. Cooper, S. J. Edgett, and E. J. Kleinschmidt, "New product portfolio management: practices and performance," Journal of Product Innovation Management, vol. 16, pp. 333-351, 1999.

[9] R. G. Cooper, E. J. Kleinschmidt, and S. J. Edgett, Portfolio Management for New Products: Perseus Books, 2001.

[10] R. W. Hahn and P. C. Tetlock, "A New Approach for Regulating Information Markets," Journal of Regulatory Economics, vol. 29, pp. 265-281, 2006.

[11] R. Hanson, "Book Orders for Market Scoring Rules," George Manson University, 2003, pp. 3.

[12] R. Hanson, "Combinatorial Information Market Design," Information Systems Frontiers, vol. 5, pp. 107-119, 2003.

[13] R. Hanson, "Decision Markets for Policy Advice," in Promoting the General Welfare: American Democracy and the Political Economy of Government Performance, E. Patashnik and A. Gerber, Eds. Washington D.C.: Brookings Institution Press, 2006.

[14] R. Hanson, "Idea Futures: Encouraging an Honest Consensus," Extropy, vol. 3, 1992.

[15] R. Hanson, "Logarithmic Market Scoring Rules for Modular Combinatorial Information Aggregation," George Mason University, 2002.

[16] R. Hanson and R. Oprea, "Manipulators Increase Information Market Accuracy," George Mason University, 2004.

[17] A. R. Hevner, S. T. March, J. Park, and S. Ram, "Design science in Information Systems research," Mis Quarterly, vol. 28, pp. 75-105, 2004.
[18] C. Hibbert, "Zocalo: An Open-Source Platform for Deploying Prediction Markets," CommerceNet Labs, 2005, pp. 21.

[19] G. E. Kersten, "Support for Group Decisions and Negotiations. An Overview," Multicriteria Analysis, pp. 332-346, 1997.

[20] M. J. Liberatore and G. J. Titus, "The Practice of Management Science in R\&D Project Management," Management Science, vol. 29, pp. 962-974, 1983.

[21] S. Liyanage, P. F. Greenfield, and R. Don, "Towards a fourth generation $R \& D$ management model-research networks in knowledge management," International Journal of Technology Management, vol. 18, pp. 372393, 1999.

[22] D. M. Pennock, "A dynamic pari-mutuel market for hedging, wagering, and information aggregation," presented at 5th ACM conference on Electronic commerce, New York, USA, 2004.

[23] C. R. Plott and K.-Y. Chen, "Information Aggregation Mechanisms: Concept, Design and Implementation for a Sales Forecasting Problem," Division of the Humanities and Social Sciences, California Institute of Technology, 2002.

[24] P. W. Rhode and K. S. Strumpf, "Manipulating Political Stock Markets: A Field Experiment and a Century of Observational Data," University of North Carolina, 2006.

[25] E. Servan-Schreiber, J. Wolfers, D. M. Pennock, and B. Galebach, "Prediction Markets: Does Money Matter?," Electronic Markets, vol. 14, pp. 243-251, 2004.

[26] M. Spann and B. Skiera, "Internet-Based Virtual Stock Markets for Business Forecasting," Management Science, vol. 49, 2003.

[27] C. Stummer and K. Heidenberger, "Interactive R\&D portfolio analysis with project interdependencies and time profiles of multiple objectives," Ieee Transactions on Engineering Management, vol. 50, pp. 175-183, 2003.

[28] J. Wolfers and E. Zitzewitz, "Five Open Questions about Prediction Markets," in Information Markets: A New Way of Making Decisions, R. W. Hahn and P. C. Tetlock, Eds. Washington D.C.: AEI Press, 2006, pp. 13-36. 